\title{
Intracanal Antibiotic Medication for Sustained Root Surface Disinfection- A Laboratory Evaluation
}

\author{
Markus Tobias Winfried Zaruba ${ }^{1}$, Tilla Filli ${ }^{1}$, Dan-Krister Rechenberg ${ }^{1}$, Thomas Thurnheer $^{2}$, \\ Thomas Attin ${ }^{1}$ and Patrick Roger Schmidlin ${ }^{1, *}$
}

${ }^{I}$ Clinic of Preventive Dentistry, Periodontology and Cariology, University of Zurich, Switzerland; ${ }^{2}$ Section for Oral Microbiology and Immunology, Institute of Oral Biology, Center of Dental Medicine, University of Zurich, Switzerland

\begin{abstract}
Purpose: To measure the release of an antibiotic mixture of ciprofloxacin, cerfuroxim and metronidazole (TreVitaMix, TVM) through human dentine and to assess the growth inhibition of Fusobacterium nucleatum. Material and Methods: Twenty-four extracted human incisors were scaled and endodontically treated. Root canals were either filled with antibiotic tri-mixture (TVM) or with the carrier material alone (propylene glycol, PG) and were coronally and apically sealed with a flowable composite. Transradicular medicament release was spectrophotometrically measured at $277 \mathrm{~nm}$ in simulated body fluid for up to 21 days. In a second part, an agar diffusion assay (F. nucleatum) with representative TVM concentrations as determined in the first part was performed to study the growth inhibition. Samples were anaerobical incubated for $48 \mathrm{~h}$ and inhibition zones were measured. Results: TVM was spectrophotometrically detectable in the immersion solution and released in decreasing concentrations up to 21 days $(222.5 \pm 65.2 \mu \mathrm{g} / \mathrm{ml}$ at day 1 and $35.1 \pm 15.6 \mu \mathrm{g} / \mathrm{ml}$ at day 21). In addition, inhibition zones were shown in the agar diffusion assay at representative TVM concentrations. The carrier material showed no antibacterial effect. Conlusion: TVM showed the potential to penetrate through dentine and to inhibit bacterial growth. Therefore, it might have the potential to disinfect the outer root surface in perio-endo lesions, but further research is needed to confirm these observations.
\end{abstract}

Keywords: Agar diffusion, bacteria, dentine, perio-endo lesion, TreVitaMix.

\section{INTRODUCTION}

Endodontic and periodontal diseases are primarily caused by bacterial infections [1-5] and studies suggest that infected root canal systems and periodontal pockets have analogical bacterial species [2, 4-8]. Untreated infections in one of these compartments can lead to symptoms or signs of disease initiation and progression inside the other tissues $[6,7,9,10]$. This can occur biderectionally, for example from the periodontium to the root canal and vice versa. Potential communication pathways in the roots are accessory canals, canal ramifications, dentinal tubules, deltas of the apical part, fins and anastomoses. Therefore, bacteria can survive not only in the root canal itself but also inside these distinctive anatomical structures [11]. Typically, in periodontal pockets more bacteria species can be found than in infected root canal systems but there is also a more complex microflora in contaminated root canals of teeth that have a coexisting periodontal and endodontic disease in comparison with teeth that have a sole periapical pathosis [4].

The treatment of such infections is challenging and some debate still exists as to which problem should be treated first, especially in combined lesions [12]. However, the root canal might be considered as an ideal space for the placement of a

*Address correspondence to this author at the Clinic of Preventive Dentistry, Periodontology and Cariology, Center of Dental Medicine, University of Zurich, Plattenstrasse 11,8032 Zurich, Switzerland;

Tel: +41 44634 3934; Fax: +41 4463443 08;

E-mail: patrick.schmidlin@zzm.uzh.ch medicament to disinfect the pathologically altered periodontal tissues as well due to their anatomical proximity in cases with necrotic pulp tissue or and insufficient root canal treatment. Thus, antibacterial endodontic drugs may represent a way to eradicate periodontal infection during root canal treatment as well, especially when using disinfecting agents applied as inter-appointment dressings in combined lesions, which can diffuse through the dental hard tissues. Desirably, this would lead to an adequate antibacterial concentration that purge the pathogens in a predictable manner at the root surface $[13,14]$.

Hoshino and co-workers found out that a combination of ciprofloxacin, metronidazole and minocycline has the ability to disinfect contaminated root dentine in vitro [15]. Sato and co-workers found that this combination was also adequate for disinfection of contaminated root dentine in situ [16]. Especially metronidazole showed the ability to penetrate through dentine [17].

A similar triple antibiotic mixture consisting of ciprofloxacin, cerfuroxim and metronidazole (TVM) (TreVitaMix, MedCem GmbH, Weinfelden, Switzerland) was further developed, which was then mainly used for revascularisation in pediatric dentistry [18-24]. Such medications, however, could be an alternative way to sustainably reach pathogenic bacteria of the periodontium provided that an adequate permeation through the dentine system is achieved by leading to a prolonged endodontic-periodontal infection control. However, the specific application of intracanal dressings as an alternative administration route to treat periodontitis is not well investigated yet. Therefore, this study aimed to assess a 
commercially available mixture of three antibiotics (TVM) and their ability to penetrate through human dentine to inhibit bacterial growth, exemplarily evaluated using Fusobacterium nucleatum (F. nucleatum).

The hypotheses were:

I) TVM has the ability to penetrate through dentine for up to 21 days

II) The determined concentrations inhibit the bacterial growth

\section{MATERIAL AND METHODS}

This investigation was divided in two parts: in the first part of the study, the concentrations of TVM release from medicated root canals were spectrophotometrically assessed in simulated bodyfluid (SBF) after a cumulative storage time of three weeks. In the second part, representative concentrations as obtained from the first study were screened for their potential to inhibit bacterial growth using an agar diffusion test. In addition, the minimally inhibitory concentration (MIC) and the minimum bactericidal concentration (MBC) of TVM were determined.

\subsection{Medicament Release Through Human Dentine}

Twenty-four extracted human incisors with only one root canal were used from the department's collection of human teeth. The extracted teeth used in this study were collected before the study during normal therapy as anonymous byproducts and kept in tap water. According to that, our Medical Ethical Board determined that the conducted research was not covered by the regulations of the "Act on Medical Research Involving Human Subjects" (METc 2009.305). Therefore it was not necessary to have a written informed consent. Before treatment, patients were elucidated about general research aim and agreed verbally. For anonymous reasons this was not documented. The crowns were removed $2 \mathrm{~mm}$ below cement-enamel junction using a handpiece (KaVo, Biberach, Germany) and a cylindrical diamond bur (Intensiv, Grancia, Switzerland) under continuous watercooling. Teeth were then endodontically treated as follows: the coronal third was widenend with crown down sequence of Gates Glidden drills size 3-2-1 (Dentsply, Ballaigues, Switzerland). The working length was measured with a ISO 10 K-File (Dentsply) by inserting the instrument into the root until the tip was just observable beyond the apical foramen. The working length was defined by subtracting $1 \mathrm{~mm}$ of the measured length. To prevent contamination of the root surface with endodontic irrigants during root canal treatment, the apical part of the root was sealed with a flowable composite (Tetric Flow Evo, Ivoclar Vivadent, Schaan, Liechtenstein) and rubber dam was applied to the coronal aspect of the root. The root canals were shaped using ProTaper ${ }^{\circledR}$ Universal instruments up to F3 (Dentsply). The root canals were rinsed with $1 \mathrm{ml}$ of a $1 \% \mathrm{NaOCl}$ solution (Hedinger, Stuttgart, Germany) after each instrument [25]. Irrigation was performed with a 30 -gauge irrigating needle $1 \mathrm{~mm}$ shorter as working length (Hawe Neos, Bioggio, Switzerland). In total, the root canals were irrigated cumulatively for $25 \mathrm{~min}$ with $\mathrm{NaOCl}$ followed by a final flush of $5 \mathrm{ml}$ of $17 \%$ EDTA (Kantonsapotheke Zürich, Zürich, Switzerland) for 5 minutes to remove the smearlayer. Finally, the canals were rinsed with $10 \mathrm{ml} 0.9 \%$ sterile saline $(\mathrm{NaCl}$, Braun Melsungen, Melsungen, Germany) to remove the EDTA. Thereafter, teeth were cut coronally to a final root length of $10 \mathrm{~mm}$. The flowable composite was chipped away using a scaler and the apical seal was renewed with the dentine bonding agent Syntac-Classic (primer \& adhesive, Ivoclar Vivadent) and Heliobond (Ivoclar Vivadent) according to the manufacturers instruction. The bonding agent was light cured for $40 \mathrm{~s}$ using a LED device (mode: HIP, $1200 \mathrm{~mW} / \mathrm{cm} 2$, Bluephase, Ivoclar Vivadent) and the apical part was freshly covered with a flowable composite (Tetric Flow Evo, Ivoclar Vivadent) and light cured again for $10 \mathrm{~s}$ (Bluephase).

For the next $24 \mathrm{~h}$, the teeth were stored at room temperature in distilled water and stratified after spectrophotometric evaluation of the blank of each tooth using a spectrophotometer (Spectra Max M2, Bucher Biotec AG, Basel, Switzerland) at a wavelength of $277 \mathrm{~nm}$. After drying of the canals with paper points (Orbis Dental, Münster, Germany), twelve roots were filled with TVM (test group; $n=12$ ) using a lentulo (size 3, Dentsply). The remaing roots were filled with the TVM carrier material (propylene glycol added with macrogolum unguentum; PG) in the same way (negative control; $\mathrm{n}=12$ ). Thereafter, the coronal part was cleaned carefully with foam pellets (Pele Tim, Voco, Cuxhaven, Germany) and $0.9 \%$ sterile saline and sealed with Syntac-Classic (Ivoclar Vivadent) and Tetric Evo Flow (Ivoclar Vivadent) as described for renewal of the apical seal. The teeth were then immersed in $2 \mathrm{ml}$ of SBF [26] and the solutions were measured using a special UV cuvette (Nr. 2722120, Portmann Instruments, Biel-Benken, Switzerland) by UV spectroscopy (Spectra Max M2) after 1, 3, 5, 7, 11, 14 and 21 days at 200 $-400 \mathrm{~nm}$. SBF was replaced with fresh solution after each measurement. Quantitative analysis of TVM was analysed using UV-spectroscopy at $277 \mathrm{~nm}$. The release of TVM was measured in $\mu \mathrm{m} / \mathrm{ml}$ after $1,3,5,7,11,14$ and 21 days.

\subsection{Leakage Test}

To exclude potential leakage of TVM through the roots, teeth were exposed to dye penetration after the medicament releasing test. For this purpose roots were covered with nail varnish (Malva, Geneva, Switzerland), embedded in epoxy resin (Paladur, Heraues Kulzer, Hanau, Germany) and subsequently placed for $20 \mathrm{~h}$ into a $0.5 \%$ fuchsin-solution (Fluka, Buchs, Switzerland). Following, the roots were cut longitudinally with a diamond saw (Isomet 1000, Buehler Ltd., Lake Bluff, IL, USA) under kerosene cooling (Fluka) and fuchsin penetration was assessed using a lightmicroscope (Tessovar, Carl Zeiss, Feldbach, Switzerland).

Normal distribution was tested with KolmogorovSmirnov-Test. Differences between time measurements and groups were tested by one-way analysis of variance (ANOVA) and Scheffé post-hoc test $(\mathrm{p}<0.05)$. Additionally, for each group separately paired t-test were used to investigate differences between individual time-points $(\mathrm{p}<$ 0.05). All analysis were performed using a commercially available statistical software (StatView Version 5, Abacus Concepts Inc., Berkley, CA, USA). 


\subsection{Agar Diffusion Test}

To study the antibacterial effects of TVM, aqueous solutions with concentrations corresponding to the results from part I of this study were prepared and tested on Fusobacterium nucleatum subsp. nucleatum (OMZ-Nr. 598).

For this purpose, petri dishes (Sterilin Limited, Newport, UK) were prepared by mixing $20 \mathrm{ml}$ of Fastidious Anaerobe Agar (acumedia ${ }^{\circledR}$, NEOGEN $^{\mathbb{B}}$ Corporation, Michigan, USA) (FAA-Agar), which was autoclaved $\left(121^{\circ} \mathrm{C}, 20 \mathrm{~min}, 1.2 \mathrm{bar}\right.$ ) with $1 \mathrm{ml}$ of the corresponding $F$. nucleatum inoculum under a laminar flow clean bench (SKAN EVZ 120, SKAN AG, Allschwil, Switzerland). Wells measuring $5 \mathrm{~mm}$ in diameter were punched out after solidification of the inoculated agar. Afterwards, wells were filled with solutions of different TVM concentrations (200-, 100-, 40-, 20-, 10- $\mu \mathrm{g} / \mathrm{ml})$, PG as carrier material, chlorhexidine $(0.2 \%)$ and SBF alone were used as control media. These concentrations correlated with those obtained from part I of the study. After $48 \mathrm{~h}$ of anaerobic incubation (Microincubator MI22NK, Scholzen Microbiology Systems AG, Necker, Switzerland) at $37{ }^{\circ} \mathrm{C}$ with $5 \%$ $\mathrm{CO}_{2}, 10 \% \mathrm{H}_{2}$, and $85 \% \mathrm{~N}_{2}$. The experiments were performed in triplicates.

The minimal radius of the inhibition zone was measured in $\mathrm{mm}$ from the external punch diameter and the area in $\mathrm{mm}^{2}$ calculated using standardized photographs (Nikon D90, Nikon Coorporation, Tokyo, Japan). All images were calibrated and analysed with a special measuring software (ImageJ 1.42q, Wayne Rasband, National Institutes of Health, USA). The area in $\mathrm{mm}^{2}$ of the outer and inner countour was measured and the difference calculated. Data were descriptively presented.

\subsection{MIC/MBC}

In addition, MIC and MBC were determined using liquid cultures in 96-well flat-bottom polystyrene microtitre test plates [27] (Nunclon Delta, Intermed, Denmark). A shematic outline of the experiment of the test plate is outlined in Fig. (3). Different TVM concentrations (10, 7.5, 5.0, 4.0, 3.0, 2.0, $1.5,1.0,0.5,0.25,0.12$ and $0 \mu \mathrm{g} / \mathrm{ml}=\mathrm{SBF}$ only) were tested again on $F$. nucleatum control wells containing $170 \mu 1$ of modified fluid universal medium (mFUM) [28] (100\% growth controls) and the test wells $150 \mu 1+30 \mu 1$ of TVM. Plates were covered with plastic lids and pre reduced for 45 min at $37^{\circ} \mathrm{C}$ in an anaerobic glove box (Microincubator MI22NK) and following inoculated with $20 \mu \mathrm{l}$ of $F$. nucleatum culture, which was adjusted to an optical density at 550 $\mathrm{nm}$ of $\mathrm{OD}_{550 \mathrm{~nm}}=0.5 \pm 0.05$ (Spectrophotometer U-2000, HITACHI, Tokyo, Japan). After $48 \mathrm{~h}$ of anaerobical incubation at $37^{\circ} \mathrm{C}$ (Microincubator MI22NK) each plate was covered with a plastic foil (Plate Sealer, R\&D Systems, Inc., Minneapolis, USA) and vigorously shaken for 10 seconds (model AM 69 micro-shaker, Dynatech Produkte AG, Kloten, Switzerland) and immediately scanned (492 nm) with a spectrophotometer (Epoch Micrplate Spectrophotometer, BioTek, Luzern, Switzerland). MIC was defined as the minimal TVM concentration that prevent visible growth.

For MBC, the corresponding TVM concentrations of MIC testing were used, inoculated and aerobically incubated for $3 \mathrm{~min}$, after which the plates were momentarily shaken and $25 \mu 1$ of the TVM test wells withdrawn and stroked on Columbia Blood Agar plates (CBA) (Difco BD ${ }^{\circledR} 279240$, DIFCO-BD - Sparks, MD, USA; Oxoid, Ltd., Basingstoke, Hamps, UK) and incubated anaerobically for $48 \mathrm{~h}$ at $37^{\circ} \mathrm{C}$. Bacterial growing was visually analysed using a stereomicroscope (Stemi 2000, Carl Zeiss, Feldbach, Switzerland).

\section{RESULTS}

\subsection{Medicament Release Through Dentine}

The release rate of the antibiotic mix and the pure carrier material as a control $(\mu \mathrm{g} / \mathrm{ml})$ up to 21 days is depicted in Fig. (1).

At baseline, no significant differences between test (TVM; $1.6 \pm 0.34 \mu \mathrm{g} / \mathrm{ml}$ ) and control group (PG; $1.5 \pm 0.4$ $\mu \mathrm{g} / \mathrm{ml})$ was observed $(\mathrm{p}>0.05)$.

In the test group, all teeth filled with TVM showed a release up to day 21 . From day $1(222.5 \pm 65.2 \mu \mathrm{g} / \mathrm{ml})$ to day $21(35.1 \pm 15.6 \mu \mathrm{g} / \mathrm{ml})$, the TVM group showed a significantly greater release at all measurement times as compared to the PG group $(p<0.01)$. No significant differences were observed in the PG group at different measurement intervals, whereas in the TVM group significant differences between day 1 and day $3(\mathrm{p}=0.0003)$ and between day 3 and day $5(\mathrm{p}$ $=0.0001)$ were observed.

The fuchsin penetration test showed no leakage at the occluding composite interface at all teeth. Thus, any leakage of the compound is presumed to occur through the root dentine walls and not through the adhesive closures.

\subsection{Agar Diffusion Test}

The minimal inhibition zones $\left(\mathrm{mm}^{2}\right)$ for the different TVM concentrations after $48 \mathrm{~h}$ are presented in Fig. (2). The PG group showed no inhibition zones whereas $0.2 \%$ CHX $(7.27 \pm 0.27 \mathrm{~mm})$ as well as TVM in all concentrations showed clear inhibition zones: However, the latter showed decreasing zones of inhibition with lower concentrations of the test material: $7.2 \pm 1.0 \mathrm{~mm}$ at $200 \mu \mathrm{g} / \mathrm{ml}, 7.0 \pm 0.3 \mathrm{~mm}$ at $100 \mu \mathrm{g} / \mathrm{ml}, 3.4 \pm 0.2 \mathrm{~mm}$ at $40 \mu \mathrm{g} / \mathrm{ml}, 2.6 \pm 0.2 \mathrm{~mm}, 20$ $\mu \mathrm{g} / \mathrm{ml}$ and $2.0 \pm 0.2 \mathrm{~mm}$ at $10 \mu \mathrm{g} / \mathrm{ml}$.

\section{3. $\mathrm{MIC} / \mathrm{MBC}$}

The minimal inhibitory concentration of TVM for $F$. $n u$ cleatum (OMZ 598) was $0.13 \mu \mathrm{g} / \mathrm{ml}$, the minimal bactericidal concentration accounted for $>10 \mu \mathrm{g} / \mathrm{ml}$.

\section{DISCUSSION}

The purpose of this study was to evaluate the ability of a mixture of three antibiotics (TVM) to penetrate through root dentine and to assess the inhibition of the growth of Fusobacterium nucleatum by an agar diffusion test with the representative concentrations as obtained from the first part. In addition, MIC and MBC concentrations for that specific bacterium were assessed in order to rate the antibacterial potential accordingly.

In the first evaluation, human teeth filled with TVM showed the highest release rate after $24 \mathrm{~h}$, which decreased until day 21. However, after 21 days there was still a 


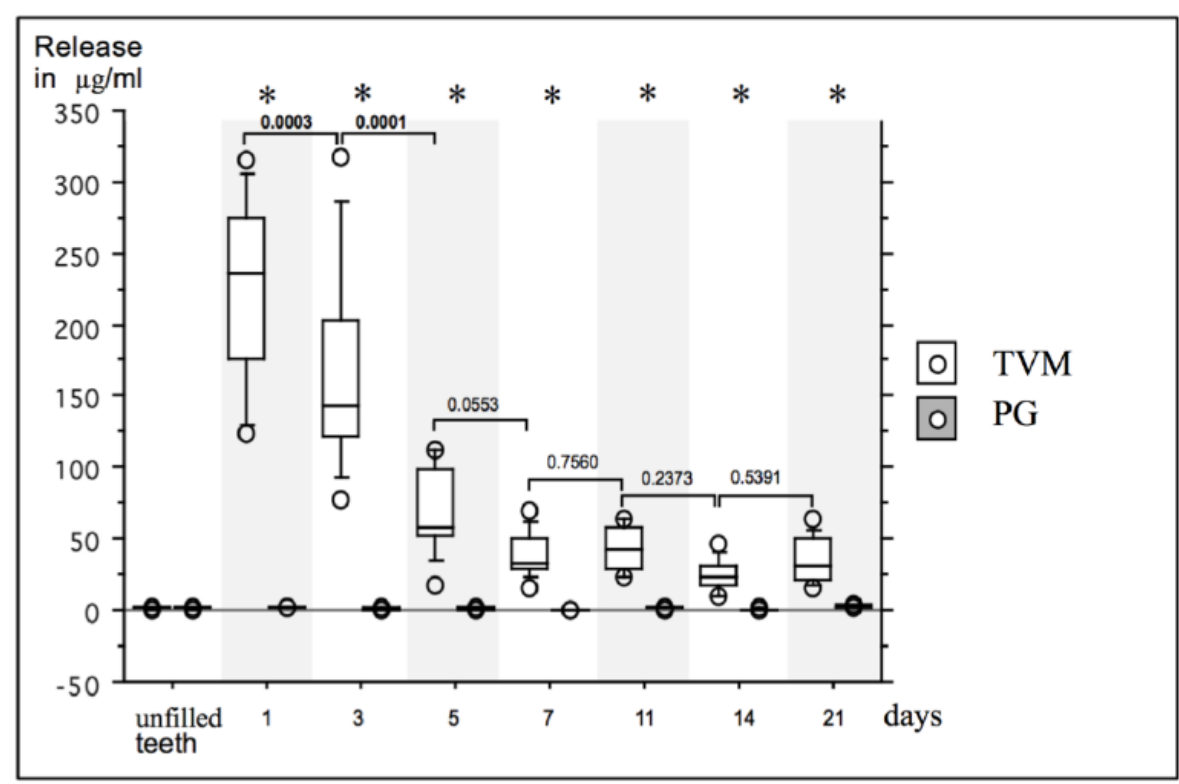

Fig. (1). Box- and whiskerplot of the release $(\mu \mathrm{g} / \mathrm{ml})$ of TreVitaMix (TVM) and propylene glycol (PG) up to $21 \mathrm{days}$. Release in $\mu \mathrm{g} / \mathrm{ml}$ at baseline (unfilled teeth) and after day 1,3,5, 7, 11, 14 and 21 are presented for TVM and PG. Asterisks indicate significant differences between TVM- and PG-group for each measurement, bars indicate significant differences within groups between different time points.

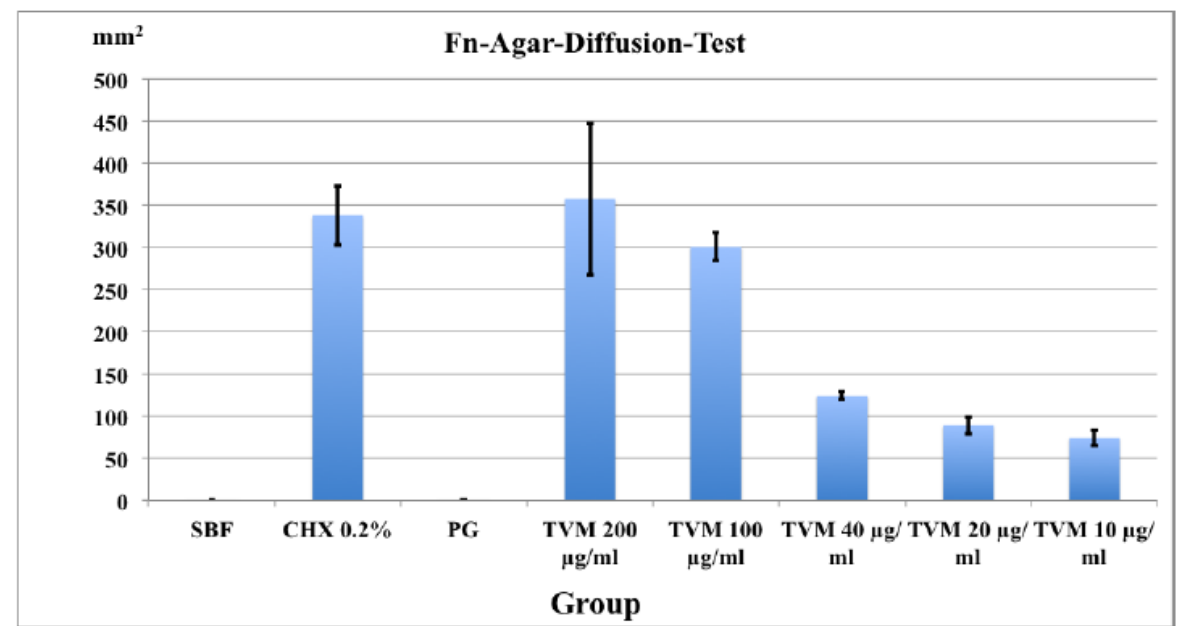

Fig. (2). Mean area of inhibition zones in $\mathrm{mm}^{2}$ and SD (in triplicates) after $48 \mathrm{~h}$ in the agar-diffusion-test with Fusobacterium nucleatum inoculated agar.

$$
\begin{array}{lllllllllllll}
1 & 2 & 3 & 4 & 5 & 6 & 7 & 8 & 9 & 10 & 11 & 12
\end{array}
$$

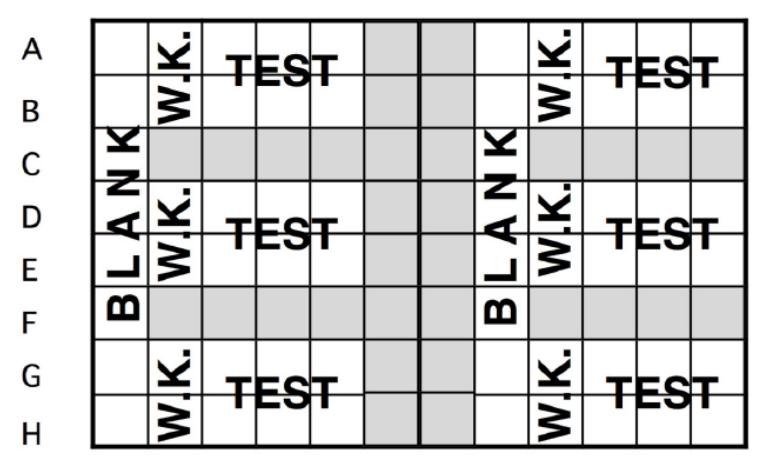

Fig. (3). Experimental arrangement of the test plates for MIC / MBC determinations of Fusobacterium nucleatum. W.K.: growth controls; TEST: respective concentrations of medicament; BLANK: Only medium as control. 
considerable release of TVM detectable. These results showed that TVM was able to penetrate through human dentine. These results are in accordance with the literature, where this effect was observed in vitro for metronidazole alone [17], CHX [29] and a triple antibiotice mixture of ciprofloxacin, metronidazole and minocycline [16]. However, Sato et al. showed this effect only up to $48 \mathrm{~h}$, whereras in the present study the release was assessed up to 21 days. The carrier material propylene glycol PG was used in combination with TVM to get a quicker medicament penetration [30]. With the leakage test performed, it was ensured that the penetration of the medicament was limited to the transdentinal pathway and not through the fillings at both ends as none of the samples showed fuchsine leakage.

The concentrations at the different timepoints of Part I obtained from the TVM group were rounded and the bacterial growth inhibiting potential was assessed in a simple agar diffusion assay using decreasing concentrations of 200, 100, 40,20 and $10 \mu \mathrm{g} / \mathrm{ml}$, respectively. The results indicated that the minimal radius of inhibition zones was related to the TVM concentrations. However, also with smaller amounts of TVM, an inhibition zone was still detectable. This may not be surprising as the determined MIC and MBC concentrations accounted for $\geq 10 \mu \mathrm{g} / \mathrm{ml}$, respectively. For the whole study, F. nucleatum was used due to the fact that is the major co-aggregation bridge organism linking early and late colonizer [31]. Therefore it was considered being a good candidate for this screening study. However, only one bacterial strain was assessed and no complex biofilms were screened, which may be considered as a shortcoming of the present study.

From a clinical perspective, penetration through different anatomical and morphological compartments should also be considered. Vasiliadis and co-workers showed that intratubular calcification was more pronounced at the mesial and distal root aspects than in the bucco-lingual counterparts [32]. Paqué et al. reported that dentine sclerosis was the most important factor affecting the permeability of root dentine [33]. It starts in the third decade of life and is a normal physiological phenomenon in the apical part and progress coronally by the age. The degree of sclerosis might therefore has a great impact on dentine permeability. Further research on this topic is therefore also necessary because the incidence of periodontitis is greater with age. Additionally scaling and root planing as well as supportive periodontal therapy could also influence by the years the amount of sclerotic dentine.

In general $\mathrm{Ca}(\mathrm{OH})_{2}$ is commonly used as intracanal medicament and concomitant the most invesitaged [34]. However, it cannot relied that calcium hydroxide is able to eliminate all pathogens in all cases - as shown by other studies $[25,35]$. This common problem is associated for all single intracanal drugs and supports that the use of more than one medicament in contaminated teeth is necessary. This can be done by separate dressings or in combination of disinfectants.

The usage of non-toxic intracanal dressings is crucial to eliminate bacteria and to support tissue repair, preferably regeneration [36]. The use of a triple antibiotic medicament might help in eliminating bacteria but wide variability was found in periodontal pathogen antibiotic resistance patterns and should concern clinicians empirically in selecting antibiotic treatment regimens for chronic periodontitis patients [37-39]. On the other hand, a combination of antibiotics would maybe also decrease the likelihood of the development of resistant bacterial strains [40]. Another previous problem of the use of antibiotics in particular tetracyclines were tooth discoloration [41]. The triple antibiotic medicament TVM used in this study exchanged minocycline as medicament by cefuroxime, which belongs to the class of the cephalosporine antibiotics and causes no discolorations [18].

In general, the common antibiotic regime during periodontal treatment is the combination of metronidazole plus amoxicillin, since it is a valuable adjunct to mechanical therapy especially in Aggregatibacter actinomycetemcomitans associated periodontal infections [42-44]. Moreover a synergistic interaction between both antiobiotics were reported [45] and using this combination as an intracanal medicament could have a great potential in eliminating particularly the periodontal pathogens. Up to the present, especially perioendo lesions have a poor long-term prognosis due to the complexity of the inflammation. TVM might be used in these situations as a viscous paste as an intracanal medicament applied with a lentulo or syringe prior to a conventional intracanal dressing material or final root canal filling for up to 21 days.

The use of antibiotic combinations as treatment regime could help the dental practitioner to give such hopeless teeth a better prognosis. But more research on this topic is still needed.

\section{CONCLUSION}

Within the limits and considerations of this in vitro study, the triple antibiotic mixture TreVitaMix as intracanal medicament showed the potential to penetrate through human dentine and inhibit bacterial growth of Fusobacterium nucleatum for prolonged periods. Therefore the medicament might have the potential to disinfect the inner as well as the outer root surface and could be an option in treating perioendo lesion. Nevertheless more reserach on this topic is needed.

\section{CONFLICT OF INTEREST}

The authors confirm that this article content has no conflict of interest.

\section{ACKNOWLEDGEMENTS}

We would like to thank Beatrice Sener and Andreas Meier for their help in the microbiology laboratory. The authors report no conflict of interests.

\section{REFERENCES}

[1] Trope M, Tronstad L, Rosenberg ES, Listgarten M. Darkfield microscopy as a diagnostic aid in differentiating exudates from endodontic and periodontal abscesses. J Endod 1988; 14: 35-8.

[2] Kobayashi T, Hayashi A, Yoshikawa R, Okuda K, Hara K. The microbial flora from root canals and periodontal pockets of nonvital teeth associated with advanced periodontitis. Int Endod $\mathrm{J}$ 1990; 23: 100-6. 
[3] Trope M, Rosenberg E, Tronstad L. Darkfield microscopic spirochete count in the differentiation of endodontic and periodontal abscesses. J Endod 1992; 18: 82-6.

[4] Kurihara H, Kobayashi Y, Francisco IA, Isoshima O, Nagai A, Murayama YA. microbiological and immunological study of endodontic-periodontic lesions. J Endod 1995; 21: 617-21.

[5] Dongari A, Lambrianidis T. Periodontally derived pulpal lesions. Endod Dent Traumatol 1988; 4: 49-54.

[6] Kipioti A, Nakou M, Legakis N, Mitsis F. Microbiological findings of infected root canals and adjacent periodontal pockets in teeth with advanced periodontitis. Oral Surg Oral. Med Oral Pathol 1984; 58: 213-20.

[7] Kerekes K, Olsen I. Similarities in the microfloras of root canals and deep periodontal pockets. Endod Dent Traumatol 1990; 6: 1-5.

[8] Didilescu AC, Rusu D, Anghel A. et al. Investigation of six selected bacterial species in endo-periodontal lesions. Int Endod $\mathrm{J}$ 2012; 45: 282-93.

[9] Langeland K, Rodrigues H, Dowden W. Periodontal disease, bacteria, and pulpal histopathology. Oral Surg Oral Med Oral Pathol 1974; 37: 257-70.

[10] Bergenholtz G, Lindhe J. Effect of experimentally induced marginal periodontitis and periodontal scaling on the dental pulp. J Clin Periodontol 1978; 5: 59-73.

[11] Abbott PV. Medicaments: aids to success in endodontics. Part 1. A review of the literature. Aust Dent J 1990; 35: 438-48.

[12] Abbott P. Endodontic management of combined endodonticperiodontal lesions. JNZ Soc Periodontol 1998; 15-28.

[13] Siqueira JFJ, Lopes HP. Mechanisms of antimicrobial activity of calcium hydroxide: a critical review. Int Endod J 1999; 32: 361-9.

[14] Orstavik D. Root canal disinfection: a review of concepts and recent developments. Aust Endod J 2003; 29: 70-4.

[15] Hoshino E, Kurihara-Ando N, Sato I, et al. In-vitro antibacterial susceptibility of bacteria taken from infected root dentine to a mixture of ciprofloxacin, metronidazole and minocycline. Int Endod J 1996; 29: 125-30.

[16] Sato I, Ando-Kurihara N, Kota K, Iwaku M, Hoshino E. Sterilization of infected root-canal dentine by topical application of a mixture of ciprofloxacin, metronidazole and minocycline in situ. Int Endod J 1996; 29: 118-24.

[17] Csukas Z, Ferenczi I, Nasz I, Banoczy J. Diffusion of metronidazole through the dentinal tubules of extracted teeth. Acta Microbiol Hung 1987; 34: 121-4.

[18] Trope M. Treatment of the immature tooth with a non-vital pulp and apical periodontitis. Dent Clin North Am 2010; 54: 313-24.

[19] Thibodeau B, Trope M. Pulp revascularization of a necrotic infected immature permanent tooth: case report and review of the literature. Ped Dent 2007; 29: 47-50.

[20] Wang X, Thibodeau B, Trope M, Lin LM, Huang GT. Histologic characterization of regenerated tissues in canal space after the revitalization/revascularization procedure of immature dog teeth with apical periodontitis. J Endod 2010; 36: 56-63.

[21] Bezgin T, Yilmaz AD, Celik BN, Sonmez H. Concentrated platelet-rich plasma used in root canal revascularization: 2 case reports. Int Endod J 2014; 47: 41-9.

[22] Chen X, Bao ZF, Liu Y, Liu M, Jin XQ, Xu XB. Regenerative endodontic treatment of an immature permanent tooth at an early stage of root development: a case report. J Endod 2013; 39: 719-22.

[23] Tawfik H, Abu-Seida AM, Hashem AA, Nagy MM. Regenerative potential following revascularization of immature permanent teeth with necrotic pulps. Int Endod J 2013; 46: 910-22.

[24] Kim JH, Kim Y, Shin SJ, Park JW, Jung IY. Tooth discoloration of immature permanent incisor associated with triple antibiotic therapy: a case report. J Endod 2010; 36: 1086-91.
[25] Bystrom A, Sundqvist G. The antibacterial action of sodium hypochlorite and EDTA in 60 cases of endodontic therapy. Int Endod J 1985; 18: 35-40.

[26] Oyane A, Kim HM, Furuya T, Kokubo T, Miyazaki T, Nakamura T. Preparation and assessment of revised simulated body fluids. J Biomed Mater Res A 2003; 65: 188-95.

[27] Shapiro S, Meier A, Guggenheim B. The antimicrobial activity of essential oils and essential oil components towards oral bacteria. Oral Microbiol Immunol 1994; 9: 202-8.

[28] Gmur R, Guggenheim B. Antigenic heterogeneity of Bacteroides intermedius as recognized by monoclonal antibodies. Infect Immun 1983; 42: 459-70.

[29] Gomes BP, Montagner F, Berber VB, et al. Antimicrobial action of intracanal medicaments on the external root surface. J Dent 2009; 37: 76-81.

[30] Cruz EV, Kota K, Huque J, Iwaku M, Hoshino E. Penetration of propylene glycol into dentine. Int Endod J 2002; 35: 330-6.

[31] Kolenbrander PE, Palmer RJJ, Periasamy S, Jakubovics NS. Oral multispecies biofilm development and the key role of cell-cell distance. Nat Rev Microbiol 2010; 8: 471-80.

[32] Vasiliadis L, Darling AI, Levers BG. The histology of sclerotic human root dentine. Arch Oral Biol 1983; 28: 693-700.

[33] Paque F, Luder HU, Sener B, Zehnder M. Tubular sclerosis rather than the smear layer impedes dye penetration into the dentine of endodontically instrumented root canals. Int Endod J 2006; 39: 1825.

[34] Athanassiadis B, Abbott PV, Walsh LJ. The use of calcium hydroxide, antibiotics and biocides as antimicrobial medicaments in endodontics. Aust Dent J 2007; 52: S64-82.

[35] Nair PN, Sjogren U, Krey G, Kahnberg KE, Sundqvist G. Intraradicular bacteria and fungi in root-filled, asymptomatic human teeth with therapy-resistant periapical lesions: a long-term light and electron microscopic follow-up study. J Endod 1990; 16: 580-8.

[36] Abbott PV, Salgado JC. Strategies for the endodontic management of concurrent endodontic and periodontal diseases. Aust Dent J 2009; 54 Suppl 1: S70-85.

[37] Rams TE, Degener JE, van Winkelhoff AJ. Antibiotic resistance in human chronic periodontitis microbiota. J Periodontol 2014;85: 160-9.

[38] Rams TE, Feik D, Mortensen JE, Degener JE, van Winkelhoff AJ. Antibiotic susceptibility of periodontal Enterococcus faecalis. J Periodontol 2013; 84: 1026-33.

[39] Veloo AC, Seme K, Raangs E, et al. Antibiotic susceptibility profiles of oral pathogens. Int J Antimicrob Agents 2012; 40: 450-4.

[40] Windley Wr, Teixeira F, Levin L, Sigurdsson A, Trope M. Disinfection of immature teeth with a triple antibiotic paste. J Endod 2005; 31: 439-43.

[41] Ahmed H.M, Abbott PV. Discolouration potential of endodontic procedures and materials: a review. Int Endod J 2012; 45: 883-97.

[42] van Winkelhoff AJ, Rodenburg JP, Goene RJ, Abbas F, Winkel EG, de Graaff J. Metronidazole plus amoxycillin in the treatment of Actinobacillus actinomycetemcomitans associated periodontitis. J Clin Periodontol 1989; 16: 128-31.

[43] Mombelli A. Antibiotics in periodontal therapy. Their use within the framework of a treatment concept. Schweiz Monatsschr Zahnmed 1998; 108: 968-81.

[44] van Winkelhoff AJ, Rams TE, Slots J. Systemic antibiotic therapy in periodontics. Periodontol 2000 1996; 10: 45-78.

[45] Pavicic MJ, van Winkelhoff AJ, Pavicic-Temming YA, de Graaff J. Amoxycillin causes an enhanced uptake of metronidazole in Actinobacillus actinomycetemcomitans: a mechanism of synergy. J Antimicrob Chemother 1994; 34: 1047-50. 